\title{
Cadherin-dependent cell aggregation is affected by decapeptide derived from rat extracellular super-oxide dismutase
}

\author{
Jean Willems ${ }^{\mathrm{a}, *}$, Erik Bruyneel ${ }^{\mathrm{b}}$, Veerle Noë ${ }^{\mathrm{b}}$, Herman Slegers $^{\mathrm{c}}$, An Zwijsen ${ }^{\mathrm{c}}$, René-Marc Mège ${ }^{\mathrm{d}}$, \\ Marc Mareel ${ }^{\mathrm{b}}$ \\ ${ }^{a}$ Interdisciplinary Research Center, KULAK, B 8500 Kortrijk, Belgium \\ ${ }^{\mathrm{b}}$ Department of Radiotherapy, Nuclear Medicine and Experimental Cancerology, University Hospital, B 9000 Gent, Belgium \\ ${ }^{\mathrm{c}}$ Department of Biochemistry, University of Antwerp, B 2610 Wilrijk, Antwerpen, Belgium \\ ${ }^{d}$ INSERM U153, Rue du Fer-à-Moulin, F 75005 Paris, France
}

Received 15 March 1995

\begin{abstract}
A synthetic HAV-containing decapeptide homologous to the amino acid sequence ${ }^{44} R-Q^{53}$ in rat extracellular superoxide dismutase $B$ affects cadherin-dependent cell aggregation. Cell lines, some of them transfected, expressing different types of cadherins were tested using in vitro cell aggregation and cell dissociation assays. A concentration-dependent inhibition of aggregation by the EC-SOD-derived HAV-containing peptide was detected only in $N$-cadherin expressing cells. These results suggest the localisation and possible protective role of EC-SOD B for cells expressing $N$-cadherin.
\end{abstract}

Key words: Superoxide dismutase; Cadherin; Cell aggregation

\section{Introduction}

Cadherins are glycoproteins responsible for $\mathrm{Ca}^{2+}$-dependent cell-cell adhesion and play an important role in morphogenesis and cancer invasion [1,2]. Modulation of the $\mathrm{Ca}^{2+}$-dependent aggregation is positively correlated with modulation of the invasion suppressor function of E-cadherin [3]. Different types such as $\mathrm{E}, \mathrm{N}$ and $\mathrm{P}$-cadherin, having a well defined tissue distribution, have been described and sequenced. They all show a high degree of homology and contain an extracellular tripeptide sequence, HAV. The latter proved to be an important recognition site for cell-cell adhesion since an $N$-cadherin derived, synthetic HAV-containing peptide can interfere with cadherin-dependent activities such as compaction of mouse embryos and neurite outgrowth [4] or myoblast fusion [5].

Although HAV was shown to be a minimal requirement for homophilic attachment, the binding specificity seems to be influenced by the minor alterations in sequences flanking the HAV motif [1]. Recently it was shown that FGF receptor, which also contains a HAV sequence, can be activated by $N$-cadherin and that an $N$-cadherin derived synthetic peptide can inhibit this response [6].

We have isolated and sequenced a new extracellular SOD from rat glioma conditioned media [7]. Although the enzyme is very homologous to other $\mathrm{Cu}-\mathrm{Zn}$ SODs, it has a unique HAV motif in its amino-terminal part, but shows no homology to any cadherin in the HAV-flanking regions.

\footnotetext{
*Corresponding author. Fax: (32) (56) 246997.
}

Abbreviations: EC-SOD, extracellular superoxide dismutase; HAV, hisala-val; all peptides are described in the one-letter code.
We wondered if this motif has any biological significance and if this extracellular SOD could influence any of the cadherindependent functions. Awaiting the expression of recombinant EC-SOD B, we tested a synthetic decapeptide ${ }^{44}$ REMHAVS$\mathrm{RVQ}^{53}$, homologous to the rat EC-SOD B sequence, together with several control peptides in cadherin-dependent aggregation and dissociation assays. We found that the EC-SOD B derived decapeptide affects only $N$-cadherin-mediated cell aggregation.

\section{Materials and methods}

\subsection{Cell lines}

ARM and 2B2 cells are both derived from mouse sarcoma S180 cells. ARM cells were transfected with and express chicken $N$-cadherin, whereas 2B2 cells were transfected with and express chicken E-cadherin [8]. These cell lines are maintained in DMEM supplemented with $15 \%$ FCS, $0.05 \%(\mathrm{w} / \mathrm{v})$ L-glutamine, $100 \mathrm{IU} / \mathrm{ml}$ penicillin and $100 \mu \mathrm{g} / \mathrm{ml}$ streptomycin.

MCF-7/AZ cells are human mammary carcinoma cells expressing human E-cadherin [9]. They are maintained in DMEM/HAM-F12 (1/1) supplemented with $5 \%$ FCS, $6 \mathrm{ng} / \mathrm{ml}$ bovine insulin, $0.05 \%(\mathrm{w} / \mathrm{v})$ L-glutamine, $100 \mathrm{IU} / \mathrm{ml}$ penicillin and $100 \mu \mathrm{g} / \mathrm{ml}$ streptomycin.

PL $\beta 2$ cells are murine L cells transfected with murine P-cadherin cDNA [10], obtained from Dr. M. Takeichi. They are grown in a $1 / 1$ mixture of DMEM and HAM F12 supplemented with 10\% FBS, 250 $\mathrm{IU} / \mathrm{ml}$ penicillin and $100 \mu \mathrm{g} / \mathrm{ml}$ streptomycin.

All media and additives were obtained from Gibco BRL (Paisley, Scotland)

\subsection{Assays for cadherin function}

Fast aggregation assay. This $\mathrm{Ca}^{2+}$-dependent cell aggregation assay was performed as described [9]. Briefly, cells were detached with trypsin in the presence of $0.04 \mathrm{mM} \mathrm{Ca}{ }^{2+}$ (to protect cadherins), suspended in medium containing soy bean trypsin inhibitor and then allowed to aggregate in a BSA pre-coated 24-well plate by Gyrotory shaking ( 85 $\mathrm{rpm}$ ) in the presence of $1.25 \mathrm{mM} \mathrm{Ca}{ }^{2+}$ and peptides or antisera (see below). PL $\beta_{2}$ cells were detached and aggregated in accordance with Nose [10]. The number of particles (cells were fixed with $2.5 \%$ glutaraldehyde) was counted with a ZM Coulter Counter (Coulter Electronics, Luton, England) at the beginning $\left(\mathrm{N}_{0}\right)$ and at the end ( $\left.30 \mathrm{~min}, \mathrm{~N}_{30}\right)$ of the Gyrotory shaking. $1-\mathrm{N}_{30} / \mathrm{N}_{0}$ was used as an index of aggregation.

Cell dissociation assay. Cells were detached from a nearly confluent monolayer and seeded at a dilution of $1 / 10$ in a 24 -well plate so that after $24 \mathrm{~h}$, we observe epithelial sheets with comparable densities in all cultures.

Half of the medium of control cultures and treated cultures is then replaced by fresh complete medium $(500 \mu \mathrm{l})$. In treated cultures appropriate dilutions of test substances are included.

As positive controls for cell dissociation we added Gc4 (see below), a monoclonal antibody that functionally inactivates chicken $N$-cadherin, at 1/50. The decapeptides, described below, were dissolved in ARM-culture medium, and were tested at different dilutions.

Cell dissociation was scored after 2 and $6 \mathrm{~h}$ of incubation by two 
independent observers on a coded well-plate; photographs were taken at that moment.

\subsection{Antisera}

Gc4 is a monoclonal antibody directed against the amino terminal part of chicken $N$-cadherin [5]. A purified immunoglobulin preparation was used at $1 / 50$ dilution.

MB2 is a monoclonal antibody directed against the extracellular part of human E-cadherin [9]. A purified immunoglobulin preparation was used at $1 / 50$ dilution.

Rabbit anti chicken E-cadherin antiserum (IgG fraction) was used at $1 / 100$ dilution [11].

PCD1 (Zymed Labs, San Francisco, USA) was used for P-cadherin dependent adhesion blockage [10]. An IgG fraction was used at 100 $\mu \mathrm{g} / \mathrm{ml}$. All antisera were preincubated with the cells for $30 \mathrm{~min}$ at $4^{\circ} \mathrm{C}$ prior to aggregation.

\subsection{Peptides}

The following peptides, homologous to sequences in the amino terminal part of cadherins or EC-SOD, were obtained from Innogenetics (Zwijnaarde, Belgium): HAV-1, REMHAVSRVQ (rat EC-SOD B); HAV-2, LRAHAVDING (human $N$-cadherin); HAV-3, LFSHAVSSNG (human E-cadherin); HAV-4, LFGHAVSENG (human P-cadherin); HAA-5, GTLHAASQVQ (human EC-SOD C); and HAA-6, REMHAASRVQ (rat EC-SOD B mutant). All peptides have a free amino terminus and are amidated at the carboxyl end. They were purified by HPLC and were over $95 \%$ pure. None of them was toxic for the cells used in this study when tested at a final concentration of $1 \mathrm{mg} / \mathrm{ml}$ as evidenced by adhesion (measured after $2 \mathrm{~h}$ ) and outgrowth (measured after $24 \mathrm{~h}$ ) of explant cultures. In the rat and human ECSOD peptides (HAV-1, HAA-5 and HAA-6), S replaces the original C, since modelling studies of the three-dimensional structure of rat ECSOD with the homologous part of other $\mathrm{Cu}-\mathrm{Zn}$ SODs showed that this cysteine residue is most probably bridged with the cysteine at position 221 (WILLEMS and DESMET, unpublished results). Therefore, and for reasons of chemical stability $C$ was changed into $S$. The peptides were dissolved either in PBS (without $\mathrm{Ca}^{2+}$ ) or in ARM-culture medium and tested at different concentrations; they were preincubated with the cells for $30 \mathrm{~min}$ at $4^{\circ} \mathrm{C}$.

\section{Results}

In order to investigate whether synthetic HAV-containing peptides affect the homophilic interaction which is mediated by cadherins, the cells used for in vitro assay must express a sufficient amount of cadherin and be able to aggregate in a $\mathrm{Ca}^{2+}$-dependent and cadherin-specific way. The ARM, 2B2,
MCF-7/AZ and PL $\beta 2$ cell lines met all these criteria and were therefore used in this study. Indeed, flow cytometric analysis and immunoprecipitations using appropriate antibodies indicated that the cell lines express a specific cadherin and have a functional cadherin-catenin complex (data not shown).

The EC-SOD B derived synthetic decapeptide HAV-1 was tested in vitro for its ability to inhibit the $\mathrm{Ca}^{2+}$-dependent aggregation of different cadherin expressing cells. As positive controls different synthetic decapeptides, homologous to the HAVcontaining domain of $\mathrm{N}, \mathrm{E}$ or $\mathrm{P}$ cadherin (HAV-2, HAV-3, HAV-4) were used. In order to underline the importance of the HAV sequence in EC-SOD B, a HAA decapeptide (HAA-5), homologous to the same domain in human EC-SOD C, together with a rat EC-SOD B derived mutant (HAA-6) were included in the test. These results are summarized in Fig. 1. At a concentration of $200 \mu \mathrm{g} / \mathrm{ml} \mathrm{HAV}-1$ scored almost as good as the control HAV-2 as an inhibitor of the aggregation of $N$ cadherin expressing ARM cells. The other peptides lacking HAV (HAA-5 and HAA-6) or having HAV-flanking regions which differ from $N$-cadherin, had no effect on aggregation. On the other hand a monoclonal anti chicken $N$-cadherin completely blocked the aggregation of ARM cells. With $2 \mathrm{~B} 2$ cells, expressing chicken E-cadherin, none of the 'human' cadherinderived peptides, nor $\mathrm{HAV}-1$ had any effect at $200 \mu \mathrm{g} / \mathrm{ml}$. Also the polyclonal antiserum against chicken E-cadherin completely abolished the ( $\mathrm{Ca}^{2+}$-dependent) aggregation.

Aggregation of MCF-7/AZ cells, which express human Ecadherin, was only affected by HAV-3 and MB2, a monoclonal antibody, shown to react with the extracellular part of human E-cadherin.

With PL $\beta 2$ cells, transfected to express murine P-cadherin, only HAV-4, homologous to the human P-cadherin, and Pcadherin specific antibodies (PCD 1) inhibited aggregation. A dose-response curve for the interaction of HAV1 and 2 on ARM cells is shown in Fig. 2. From these results it is apparent that both peptides have nearly the same potency since they give a $50 \%$ inhibition of aggregation at concentrations of about 75 $\mu \mathrm{g} / \mathrm{ml}$.

Furthermore, the inhibition of cadherin function was confirmed using a cell dissociation assay. Again, the EC-SOD B

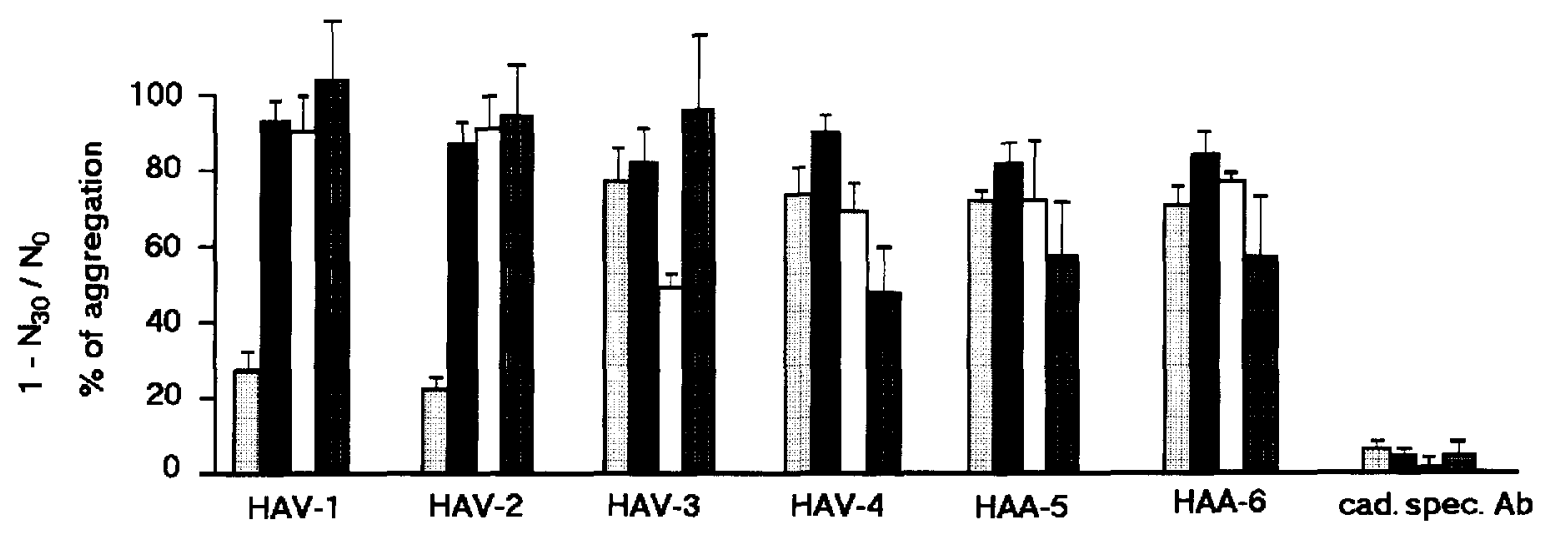

ARM $\square 2 B 2 \square$ MICF-7IAZ PLB2

Fig. 1. Fast aggregation assay on cadherin expressing cells. ARM, 2B2, MCF-7/AZ and PL $\beta 2$ cells were incubated in the presence of $200 \mu \mathrm{g} / \mathrm{ml}$ decapeptide or a specific anti-cadherin. Aggregation indexes are calculated as described and expressed as a percentage in relation to those obtained for cells aggregated in $\mathrm{Ca}^{2+}$-containing medium without decapeptide or antiserum (set $=100 \%$ ). Each value (mean \pm S.D.) is the result of at least four experiments. 
derived decapeptide only affected ARM cells. As expected a similar dissociation-inducing effect was only obtained by HAV2 and the $\mathrm{Gc} 4$ antiserum (Fig. 3).

\section{Discussion}

In this report we show that a decapeptide homologous to part of the rat EC-SOD B sequence can interfere with cadherindependent cell aggregation. EC-SOD B is well related to intracellular $\mathrm{Cu}-\mathrm{Zn}$ SOD [7], the three dimensional structure of which has been studied in detail [12]. From our modelling studies (unpublished results) we conclude that the HAV containing sequence should be exposed at the surface, capable to interact with surrounding molecular targets. Therefore, awaiting the recombinant enzyme, the decapeptide might be a good mimic for EC-SOD B.

HAV-containing peptides have been used to interfere with cadherin-mediated cell aggregation $[4,5]$. The peptides used in this study support the hypothesis that the HAV sequence plus some flanking amino acids make up the important adhesion recognition sites of cadherins. Indeed, only our HAV-containing peptides like HAV-2, 3 and 4 are significantly active on appropriate target cells, whereas HAA-containing peptides are not. The HAV-flanking amino acids seem to be important for the type of cadherin which is affected. This selectivity is illustrated by the fact that 2B2 cells which express chicken E cadherin (containing the LLSHAVSASG sequence) are not influenced by the 'human-E' nor by the 'human-P' decapeptides.

Even HAV-4, which only differs from $\mathrm{HAV}-3$ by two mutations, has no activity on HAV-3 sensible cells. Yet, the EC-SOD derived HAV-1 peptide, which, apart from the HAV sequence, has no homology to any of the cadherins, clearly affects $N$ cadherin expressing cells. This effect could be functionally important since HAV-1 is at least as active as HAV-2 in our assays (Fig. 2).

These results could implicate that EC-SODs are not evenly distributed in the circulation or in extracellular spaces.

In this context it is noteworthy that human EC-SOD $\mathrm{C}$ is bound to heparin sulphate proteoglycans in the extracellular matrix, due to its polybasic carboxyl terminal tail [13]. This was shown by intravenous injections of heparin which led to a subsequent increase of EC-SOD C in the circulation [14]. Although EC-SOD B has an analogous (but not identical) car-

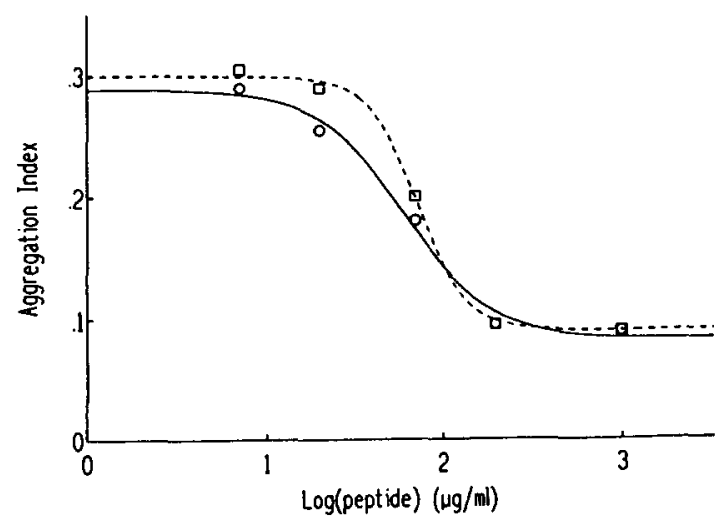

Fig 2. Dose-response curve for HAV-1 (full line) and HAV-2 (dashed line) on ARM cells in the fast aggregation assay. Ordinate: aggregation index; abcissa: concentration of decapeptide.
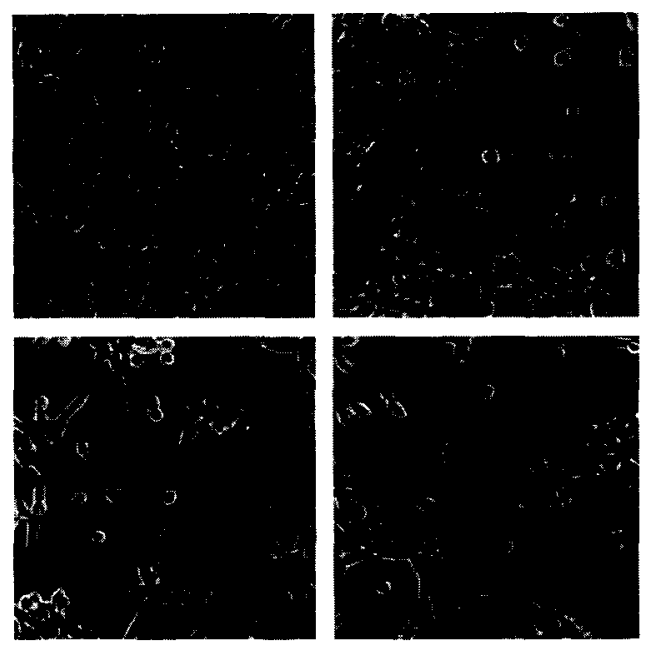

Fig. 3. Cell dissocation assay on ARM cells. Cells were incubated as described in section 2 and subsequently treated with PBS (a), Gc4 (1/50 in PBS) (b), HAV-1 (c) or HAV-2 (d). Pictures were taken after $6 \mathrm{~h}$ of treatment. The scale bar $=100 \mu \mathrm{m}$.

boxyl terminus, heparin injection could not increase the amount of EC-SOD B in the circulation [14]. Therefore, since rat $\mathrm{EC}-\mathrm{SOD} \mathrm{B}$ has a unique $\mathrm{HAV}$ motif we suggest that, due to this cadherin-binding sequence, it is found in equilibrium with $N$-cadherin expressing cell surfaces.

Rat EC-SOD B is indeed produced by glioma cells [7] and in the epididymis [15]. It was recently shown in the rat that the distribution of different types of cadherins is highly regulated during spermatogenesis, transport and maturation of the sperm in the epididymis. In rat testes, no E-cadherin mRNA is detectable. On the other hand the P-cadherin level sharply dropped in the first weeks after birth while the $N$-cadherin level increased until the time of shedding of the first sperm [16]. Maturation of the sperm takes place in the epididymis which expresses $\mathrm{E}$ but not $\mathrm{N}$-cadherin [17]. Therefore, rat EC-SOD, having an affinity for $N$-cadherin, could protect the maturing sperm cells against toxic superoxide. Furthermore neurons express $N$-cadherin and are also very susceptible to reactive oxygen intermediates. Here too, EC-SOD B could be very useful as a protector of NO (as a neurotransmitter) and avoiding the formation of the very cytotoxic peroxynitrite, a result of the reaction of NO with superoxide.

In conclusion, our observations suggest that rat EC-SOD B, due to its unique HAV motif, is probably located at well restricted and very specific sites, protecting the latter against the noxious effects of superoxide.

Acknowledgements: We thank Sigrid Vanryckeghem for typing the manuscript and Lieve Baeke and Stefan Vermeulen for technical assistance. This work was supported by Belgisch Werk tegen Kanker (grant to A.Z.) and by NFWO Grants to J.W. and H.S. (Levenslijn No. 7.0016.94) and to M.M. (No. 33004292). V.N. is a research associate of the NFWO.

\section{References}

[1] Geiger, B. and Ayalon, O. (1992) Annu. Rev. Cell Biol. 8, 307-332.

[2] Van Roy, F. and Mareel, M. (1992) Trends Cell Biol. 2, 163-169.

[3] Vleminckx, K.L., Deman, J.J., Bruyneel, E.A., Vandenbossche, 
G.M., Keirsebilck, A.A., Mareel, M.M. and Van Roy, F.M. (1994) Cancer Res. 54, 873-877.

[4] Blaschuk, O.W., Sullivan, R., David, S. and Pouliot, Y. (1990) Dev. Biol. 139, 227-229.

[5] Mege, R.M., Goudou, D., Diaz, C., Nicolet, M., Garcia, L., Geraud, G. and Rieger, F. (1992) J. Cell Sci. 103, 897-906.

[6] Williams, E.J., Furness, J., Walsh, F.S. and Doherty, P. (1994) Neuron 13, 583-594.

[7] Willems, J., Zwijsen, A., Slegers, H., Nicolai, S., Bettadapura, J., Raymackers, J. and Scarcez, T. (1993) J. Biol. Chem. 268, 24614 24621.

[8] Mege, R.M., Matsuzaki, G., Gallin, W.J., Goldberg, J.I., Cunningham, B.A. and Edelman, G.M. (1988) Proc. Natl. Acad. Sci. USA 85, 7274-7278.

[9] Bracke, M.E., Vyncke, B.M., Bruyneel, E.A., Vermeulen, S.J., Debruyne, G.K., Van Larebeke, N.A., Vleminckx, K., Van Roy, F.M. and Mareel, M.M. (1993) Br. J. Cancer 68, 282-289.
[10] Nose, A., Nagafuchi, A. and Takeichi, M. (1988) Cell 54, 993 1001.

[11] Vleminckx, K., Vakaet, L., Mareel, M., Fiers, W. and Van Roy, F. (1991) Cell 66, 107-119.

[12] Parge, H.E., Hallewell, R.A. and Tainer, J.A. (1992) Proc. Natl. Acad. Sci. USA 89, 6109-6113.

[13] Adachi, T. and Marklund, S.L. (1989) J. Biol. Chem 264, 85378541.

[14] Karlsson, K. and Marklund, S.L. (1988) Biochem. J. 255, 223-228.

[15] Perry, A.F.C., Jones, R. and Hall, L. (1993) Biochem. J. 293 21-25.

[16] Cyr, D.G., Blaschuk, O.W. and Robaire, B. (1992) Endocrinology 131, 139-145.

[17] Cyr, D.G., Hermo, L., Blaschuk, O.W. and Robaire, B. (1992) Endocrinology 130, 353-363. 